\title{
REGIONAL CHARACTERISTICS OF SNOW COVER IN CENTRAL JAPAN \\ FROM THE STANDPOINTS OF STABLE ISOTOPIC PROCESSES, CHEMICAL CONTENT AND SNOW METAMORPHISM \\ Abstract
}

by

\author{
O. Watanabe, S. Takgnaka, H. Takahara, H. ImA
}

Water Research Institute, Nagoya University, Nagoya, Japan

Facing the Sea of Japan, the coasts of Honshu and Hokkaido form one of the most heavily snow-covered regions in the world. It is rarely the case that heavy snow cover occurs in a region having such a high density of population. A sub-tropical climate predominates in summer, and a sub-polar climate in winter.

Regional characteristics of the snow cover are complicated, reflecting the unique geographical conditions; the distance along the coast, for example, is more than $1500 \mathrm{~km}$, spanning a latitude range of $35^{\circ}-44^{\circ} \mathrm{N}$. The Tsugaru Strait forms a major dividing line for snow cover characteristics; the climate to the north of it is relatively cold with less snow while the south is warmer with heavy snow. In addition, yearly variation of solid precipitation increases toward the south.

Field research was carried out during 1979-1983 in the Uono River region in the central part of Honshu, and in the Sho, Tedori and Kuzuryu River regions a little to the south. Characteristics of snow cover in these regins were studied from the standpoints of the stable isotopic processes, content and distribution of chemical composition and snow metamorphism relating to the concept of glacier zoning. The results obtained from the field research and laboratory analyses can be summarized as follows:

(1) Another unique geographical characteristic of this snow-covered region is the fact that the snow cover is found in a relatively narrow range, $50-100 \mathrm{~km}$ from the coast to the backbone mountains generally ranging in altitude from $1000-3000 \mathrm{~m}$. So the variation of characteristics occurs in a relatively short distance with altitude change. In the central and the southern parts of Japan, snow cover can be characterized by temperate snow metamorphism. The process and its amount of melt-water percolation play an essential role in snow metamorphism so that the transition of the saturation line is more important as a climatic or cryospheric environmental indicator.
According to these field observations, the snow metamorphism proceeds through three stages (I-III). A typical feature of stage II is the formation of an ice increment (crust, lens). In stage III, snow cover is completely transformed to loose granular snow, which causes whole-depth avalanches in the mountains. Although glaciers are not found in Japan, perennial ice patches transformed from snow cover are found. The mechanism of ice formation is related to the process of stage II.

(2) Deterioration of cold air mass blowing from the Eurasian Continent occurs during the crossing of the relatively warm Sea of Japan. Water vapour which the air picks up from the sea is transformed to snowparticles during cumulus convective circulation over the sea, and forced ascent along the slope of the backbone mountains.

Snow cover in the Japanese archipelago is a result of the climatic interaction between the continent, the sea and the archipelago. For understanding this interaction through the transportation and distribution of stable isotopes and chemical content, field observations and systematic sampling work were carried out at two fixed stations and 21 stations for mobile observations in the regions of the Sho, Tedori and Kuzuryu Rivers during 1981-1983.

A distinct relationship between the $\sigma^{18} \mathrm{O}$ value of falling snow and the sruface temperature was clearly found. In this connection, a method identifying a snow layer formed in a certain snowfall period is developed using the fact that the sharp decreasing peaks of $\sigma^{18} \mathrm{O}$ are related to temperature depression during the night.

Using this method, the sequence of snow cover, layering of the 1982-1983 winter was clearly identified, and the initial isotopic and chemical content and their changes in their respective layers were revealed. 